\title{
Thermal Analysis of Direct Liquid-Immersed Solar Receiver for High Concentrating Photovoltaic System
}

\author{
Xinyue Han, Qian Wang, Jun Zheng, and Jian Qu \\ School of Energy and Power Engineering, Jiangsu University, Zhenjiang, Jiangsu 212013, China \\ Correspondence should be addressed to Xinyue Han; hanxinyue@ujs.edu.cn
}

Received 31 May 2015; Revised 21 July 2015; Accepted 27 July 2015

Academic Editor: Yanfa Yan

Copyright ( 2015 Xinyue Han et al. This is an open access article distributed under the Creative Commons Attribution License, which permits unrestricted use, distribution, and reproduction in any medium, provided the original work is properly cited.

\begin{abstract}
Concentrator solar cells that operate at high solar concentration level must be cooled. In this paper, direct liquid immersion cooling of triple-junction solar cells ( $\mathrm{InGaP} / \mathrm{InGaAs} / \mathrm{Ge}$ ) is proposed as a heat dissipation solution for dense-array high concentrating photovoltaic (HCPV) systems. The advantages of triple-junction CPV cells immersed in a circulating dielectric liquid and dish HCPV technology are integrated into a CPV system to improve the system electrical conversion efficiency. An analytical model for the direct liquid-immersed solar receiver with triple-junction CPV cells is presented. The main outputs of the model are the components temperatures of the receiver and the system electrical efficiency. The influence of concentration factor, mass flow rate, and inlet liquid temperature on the operating temperature of the triple-junction CPV cells and the system electrical conversion efficiency are discussed. It is shown that the system electrical conversion efficiency is very high for a wide range of operating conditions. The three operating parameters have a major effect on the operating temperature of the triple-junction CPV cells and, by extension, system output power. The flow rate selection should match concentration factor to keep the triple-junction CPV cells temperature lower and increase the electrical conversion efficiency of the dense-array HCPV system.
\end{abstract}

\section{Introduction}

Solar photovoltaic (PV) systems are attracting a lot of attention as electrical power sources that can complement or replace the fossil and nuclear fuels power generation systems. However, the PV systems costs are still not competitive with the conventional power generation systems. Concentrating photovoltaic (CPV) systems provide economic advantages by combining cheap concentrators with high efficiency solar cells. Triple-junction solar cells with conversion efficiencies $46.0 \%$ are currently available [1]. Furthermore, a costeffective use of high performance multijunction solar cells is enabled in high concentrating photovoltaic (HCPV) systems. The concentration factor is higher than 300 suns. HCPV technology had been investigated for a long time. In the future, the cell efficiency will increase and the systems costs will be reduced further. Therefore, the HCPV market using high efficiency multijunction solar cells will be increasing continuously [2].

However, concentrator solar cells that operate at high solar concentration factor must be cooled, because much of the incident solar energy that is not converted to electricity appears as heat during the HCPV systems operation. This heat will in turn reduce the system electrical efficiency, and even the cells are subject to thermal damage. Thus, a good heat rejection system is essential for HCPV system [3]. Actually, many cooling methods have been proposed with different cooling performance. Modular HCPV systems are usually passively cooled. Araki et al. [4] proved that the cell temperature would rise only $18^{\circ} \mathrm{C}$ when the $\mathrm{CPV}$ module with the designed passive heat dissipation device operated as high as 500 suns. Sun et al. [5] predicted the electrical performance and thermal performance of the minidish HCPV system under natural air cooling for different heat sink designs. Wang et al. [6] investigated the performance of HCPV solar cell modules with passive cooling through Computational Fluid Dynamics (CFD) simulations. The results indicated that the maximum cell temperature depends on the direct normal irradiance and ambient temperature. In contrast, central receiver systems use heliostats or a dish to focus sunlight on a bigger densely packed CPV cells. Therefore, in these densearray HCPV systems, the passive cooling is not sufficient 
and the active cooling is used to keep the CPV cells from overheating. Lasich [7] proposed a water cooling circuit for a dense-array HCPV system with silicon CPV cells. The circuit is reported to be able to reject $500 \mathrm{~kW} / \mathrm{m}^{2}$ from solar cells and to keep the CPV cell temperature at about $40^{\circ} \mathrm{C}$. Chong and Tan [8] proposed an automotive radiator for the heat dissipation of the dense-array CPV system and demonstrated the feasibility of the proposal through theoretical modeling and experiment. In addition, Ho et al. [9] analyzed the potential of increasing HCPV system efficiency by twophase flow cooling. Results indicated that the decisive factor for improving cell efficiency was the saturation temperature of the working fluid, which is influenced by many design parameters.

In order to minimize the thermal contact resistance between solar cells and heat sink, the direct liquid immersion cooling has been proposed for the thermal management in the CPV systems. With direct liquid immersion cooling, bare $\mathrm{CPV}$ cells are immersed in a circulating dielectric liquid. So, the contact thermal resistance between the CPV cell and heat dissipation system is reduced. Further, the heat can be taken away by both the front and rear cell surfaces instead of just the rear surface, as in conventional active cooling. Ugumori and Ikeya [10] observed that the photocurrent of solar cells operated in liquids increases with the increase in the permanent dielectric moment of liquid molecules. Abrahamyan et al. [11] found that a dielectric liquid thinfilm can increase the efficiency of common silicon solar cells by $40-60 \%$. In addition, Wang et al. [12] and Han et al. [13] conducted some tests and described a possible mechanism for increased silicon solar cell performance when immersed in liquids. Sun et al. [14] studied the performance of silicon CPV cells in a liquid-immersed linear CPV receiver. The results showed that the low and uniform cell temperature can be maintained in the receiver and the receiver channel can be designed narrower to further reduce the liquid holdup. Zhu et al. [15] reported that the silicon CPV module can be reduced to $45^{\circ} \mathrm{C}$ when 250 -sun CPV system was cooled by direct deionized water immersion, but the results also showed that the electrical performance of the module degraded after a fairly long time immersion in the water.

In this paper, the direct liquid immersion cooling is proposed for densely packed triple-junction solar cells thermal management in the HCPV systems. The novelty of our study is to combine the advantages of triple-junction CPV cells immersed in a circulating dielectric liquid and dish high concentrator photovoltaic technology into the dense-array HCPV system to improve the system electrical conversion efficiency. In order to analyze the performance of the novel central receiver, that is, a direct liquid-immersed solar receiver with densely packed triple-junction CPV cells for the HCPV system, an analytical model based on energy balance is developed. The components temperatures of the receiver and the related energy flows are calculated in detail through this model. The model can be used to evaluate both triple-junction CPV cells temperature and the system electrical efficiency related to the concentration factor, mass flow rate, and inlet liquid temperature. Through this investigation, the feasibility of our proposal can be proved and the signification of liquid immersion cooling in maintaining the good performance of dense-array HCPV system can be justified.

\section{HCPV System Description}

The proposed dense-array HCPV system is mainly composed of a dish concentrator, a direct liquid-immersed solar receiver with densely packed triple-junction CPV cells, and a tracking unit.

2.1. Concentrating and Tracking System. Dish concentrator is typically used for HCPV systems. But conventional parabolic dishes have a problem that the incident flux distribution is not uniform causing the system efficiency reduction. Then, in this study, the reflecting dish is assembled of 120 flat mirrors to achieve a uniform incident flux distribution. Further, the concentration factor can be adjusted. Every mirror facet is about $100 \mathrm{~cm}^{2}$. The reflectivity of the dish concentrator is about $94 \%$.

It is well known that concentrators are limited to collecting only the beam radiation. Therefore, the two-axis tracking unit is used to improve the dense-array HCPV system efficiency. Further, the simpler and more accurate algorithm that determined the sun position from the solar literature reviewed by Blanco-Muriel et al. [16] is used here. In addition, a programmable logic controller system is developed and manufactured for the tracking unit.

2.2. Direct Liquid-Immersed Solar Receiver. The direct liquidimmersed solar receiver is composed of densely packed triple-junction CPV solar module, a dielectric liquid circulating in the receiver body, electrical connections, and a transparent glass cover oriented towards the focused sunlight. The design concepts of the direct liquid-immersed solar receiver are given in Figure 1.

The densely packed CPV solar module uses InGaP/ InGaAs/Ge triple-junction solar cell, which is manufactured by Tianjin Lantian Solar Tech Co., Ltd. The single cell size is $10 \mathrm{~mm}$ long and $10 \mathrm{~mm}$ wide, with a typical efficiency of $39.2 \%$ at 500 suns $\left(\mathrm{AM} 1.5 \mathrm{D}, 25^{\circ} \mathrm{C}\right)$. The cells are attached on the copper-clad insulated metal substrate to form module. The module includes 25 triple-junction CPV solar cells arranged in five rows. The total module is $0.14 \mathrm{~m}$ long and $0.08 \mathrm{~m}$ wide. The active area of the module including gaps between cells is about $28 \mathrm{~cm}^{2}$. Positive and negative electrodes as well as the bypass diodes for each cell are installed at the outer edge in an area protected from radiant flux. In HCPV system, the CPV cells also experience high operating temperature. To avoid the solar cells overheating, the heat is dissipated by dimethyl silicon oil flowing in a liquid channel in which the module has been located. The heat from the solar cells is transferred to dimethyl silicon oil through convection heat transfer and conduction heat transfer. The size of the liquid channel can be changed with the CPV solar modules to provide effective cooling. 


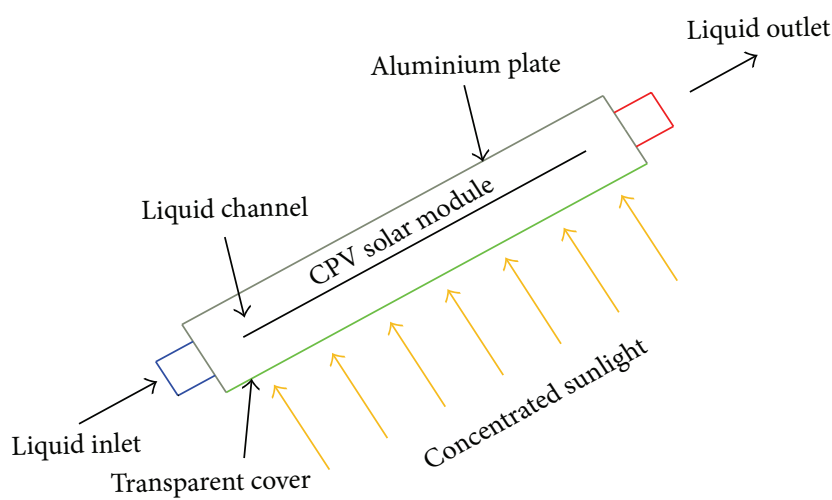

FIGURE 1: Cross-section of direct liquid-immersed solar receiver.

\section{Mathematic Description}

The theoretical research done in modeling CPV receiver based on direct liquid immersion cooling has not seen many development activities. A numerical model for the receiver and the cooling system of a CPV system was developed by Mahderekal et al. [17], which was used to simulate the whole system performance and then used to choose the input parameters. Chong and Tan [8] established a model of the automotive radiator cooling system for the CPV system. It allows detailed analysis of the heat transfer rate in the function of temperature difference between ambient and radiator for a wide range of flow rates and wind speeds. Ho et al. [9] published a steady-state model of the two-phase cooling system to forecast cell temperature distributions and cell efficiencies for PV cells under 100 suns. In addition, Lee et al. [18] studied the influences of different design parameters on thermal performance of the cooling system for CPV system through CFD simulation. Buonomano et al. [19] constructed a 1D model of the heat flow in a watercooled CPV receiver. They found that the model seems to give reasonable results even when the module exposed to the concentration factor up to 1000 suns. Al-Amri and Mallick [20] established a model based on finite difference approach to forecast the maximum temperature of the solar cells, which were cooled by air-mixed convection without and with the radiation interaction.

In the present case, the models mentioned above can not be used due to the use of direct liquid immersion cooling and triple-junction CPV cells in the dense-array HCPV system. Therefore, in order to forecast the electrical performance of the dense-array HCPV system with direct liquid immersion cooling, a zero-dimensional energy balance model under steady-state conditions is developed. This model can be enough fast for approximate steady-state yearly simulation. Higher dimensional models to simulate the heat transfer in CPV solar module should be costly considering the computational aspect.

Figure 2 shows the thermal network describing the energy flows among the components of the direct liquid-immersed solar receiver and the surroundings. It should be noted that the copper-clad insulated metal substrate on which the cells are mounted is neglected due to its higher heat conductivity and negligible thickness. The aim of the thermal network is to analyze the CPV triple-junction CPV cells temperature immersed in circulating dimethyl silicon oil. The triplejunction CPV cells temperature is very important for achieving the electrical output. Based on the thermal network, the model is presented in the next several paragraphs.

3.1. Energy Balances. The energy balance for aluminium plate is given by the following equation, and the receiver edges are ignored here:

$$
\begin{aligned}
Q_{p}+ & h_{p a} A_{p}\left(T_{a}-T_{p}\right)+h_{r, p s} A_{p}\left(T_{s}-T_{p}\right) \\
& +h_{p f} A_{p}\left(T_{m}-T_{p}\right)+h_{r, p c} A_{\text {modu }}\left(T_{c}-T_{p}\right)=0,
\end{aligned}
$$

where $Q_{p}$ is the thermal energy absorbed by aluminium plate. $T_{p}$ is the temperature of aluminium plate. $T_{a}$ is the ambient temperature. $T_{s}$ is the equivalent sky temperature. $T_{m}$ is the mean liquid temperature. $T_{c}$ is the triple-junction CPV cells temperature. $A_{p}$ and $A_{\text {modu }}$ are the surface areas of aluminium plate and CPV solar module, respectively.

The energy balance for triple-junction CPV cells can be written as follows:

$$
\begin{aligned}
Q_{c}+ & h_{r, p c} A_{\text {modu }}\left(T_{p}-T_{c}\right)+h_{r, g c} A_{\text {modu }}\left(T_{g}-T_{c}\right) \\
& +h_{c f 1} A_{\text {modu }}\left(T_{m 1}-T_{c}\right)+h_{c f 2} A_{\text {modu }}\left(T_{m 2}-T_{c}\right) \\
= & 0,
\end{aligned}
$$

where $Q_{c}$ is the thermal energy absorbed by triple-junction CPV cells. $T_{m 1}$ and $T_{m 2}$ are the mean liquid temperature of one immersion liquid flowing the module front surface and another immersion liquid flowing the module rear surface, respectively.

The energy balance for immersion liquid is as follows:

$$
\begin{aligned}
h_{c f 1} & A_{\text {modu }}\left(T_{c}-T_{m 1}\right)+h_{c f 2} A_{\text {modu }}\left(T_{c}-T_{m 2}\right) \\
& +h_{p f} A_{p}\left(T_{p}-T_{m 2}\right)+h_{g f} A_{g}\left(T_{g}-T_{m 1}\right) \\
= & m_{f} c_{f}\left(T_{f_{o}}-T_{f_{i}}\right),
\end{aligned}
$$

where

$$
T_{m}=T_{m 1}=T_{m 2}=\frac{T_{f_{i}}+T_{f_{o}}}{2}
$$

$m_{f}$ is mass flow rate of immersion liquid, $c_{f}$ is specific heat of immersion liquid, $T_{f_{i}}$ and $T_{f_{o}}$ are the inlet temperature and the outlet temperature of immersion liquid, $T_{g}$ is the temperature of glass cover, and $A_{g}$ is the glass cover area.

The energy balance for glass cover is given by

$$
\begin{aligned}
Q_{g}+ & h_{r, g c} A_{\text {modu }}\left(T_{c}-T_{g}\right)+h_{r, d g} A_{g}\left(T_{d}-T_{g}\right) \\
& +h_{a g} A_{g}\left(T_{a}-T_{g}\right)+h_{g f} A_{g}\left(T_{m 1}-T_{g}\right)=0,
\end{aligned}
$$

where $Q_{g}$ is the thermal energy absorbed by glass cover and $T_{d}$ is the temperature of dish concentrator. 


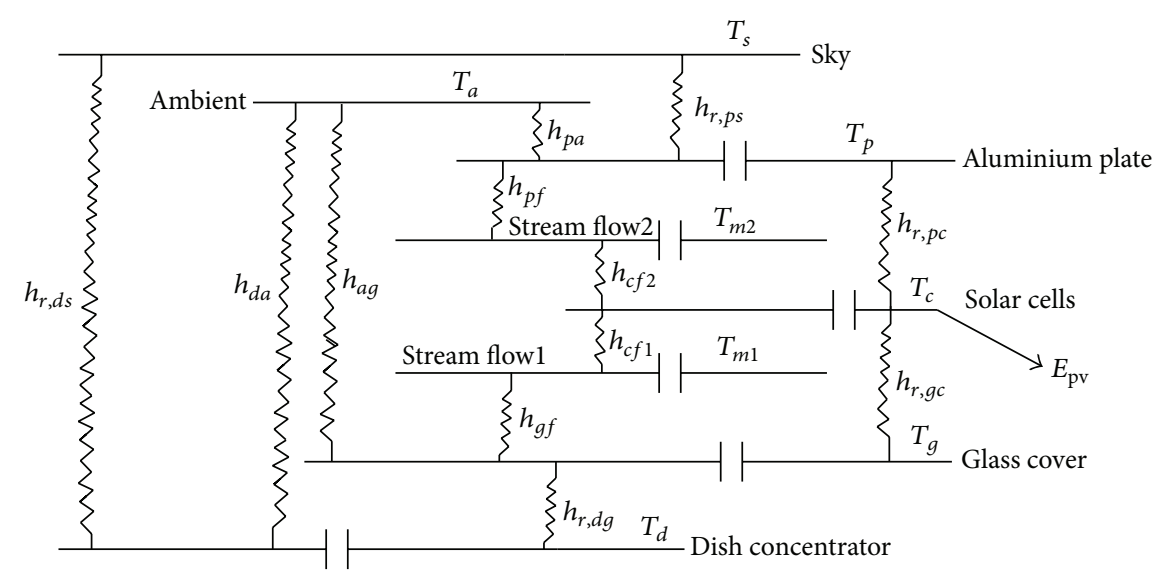

FIGURE 2: Thermal network describing a direct liquid-immersed solar receiver. The thermal resistances are modeled using the respective heat transfer coefficients $h_{i}$.

The energy balance for dish concentrator is

$$
\begin{aligned}
Q_{d}+ & h_{r, d g} A_{g}\left(T_{g}-T_{d}\right)+2 h_{d a} A_{d}\left(T_{a}-T_{d}\right) \\
& +h_{r, d s} A_{d}\left(T_{s}-T_{d}\right)=0,
\end{aligned}
$$

where $A_{d}$ is the concentrator area. In this case, the left terms of (6) are as follows: the irradiance absorbed by the concentrator $Q_{d}$, the radiation heat transfer between the glass cover and the dish concentrator, the convection heat transfer at the front surface of the concentrator, and the convection heat transfer at the back surface, as well as the radiation heat transfer between the dish concentrator and the sky.

3.2. Solar Energy Model. The irradiance converted into thermal energy absorbed by aluminium plate, triple-junction solar cells, glass cover, and dish concentrator are given by

$$
Q_{p}=A_{p} I_{\text {tot }} \alpha_{p}
$$

where $I_{\text {tot }}$ is the total radiation and $\alpha_{p}$ is the absorptance of aluminium plate:

$$
\mathrm{Q}_{c}=\alpha_{c} G-E_{\mathrm{PV}}
$$

where

$$
G=A_{\mathrm{PV}} I_{b} C_{\mathrm{PV}} \eta_{\mathrm{opt}} \cdot
$$

$\alpha_{c}$ is absorptance of triple-junction CPV cells, $G$ is the radiation focused on the $\mathrm{CPV}$ surface, $E_{\mathrm{PV}}$ is the power output, $A_{\mathrm{PV}}$ is the active area of the CPV module, $I_{b}$ is the beam radiation, and $C_{\mathrm{PV}}$ is the concentration factor. $\eta_{\mathrm{opt}}$ is the system optical efficiency, which is considered as a constant value [21]:

$$
Q_{g}=A_{g} I_{b} C_{\mathrm{PV}} R_{d} \alpha_{g},
$$

where $\alpha_{g}$ is the absorptance of glass cover and $R_{d}$ is the reflectivity of the concentrator:

$$
Q_{d}=A_{d} I_{\text {tot }} \alpha_{d}
$$

where $\alpha_{d}$ is the absorptance of the concentrator.
3.3. Electrical Model. The power output $E_{\mathrm{PV}}$ is considered to depend on the irradiance and the solar cell temperature, which is described as follows:

$$
E_{\mathrm{PV}}=G \eta_{r}\left[1+\beta_{r}\left(T_{c}-T_{r}\right)\right],
$$

where $\eta_{r}$ is the electrical efficiency of the triple-junction CPV cells at a reference temperature $T_{r}$. $T_{r}$ is typically set to be $25^{\circ} \mathrm{C}$. $\beta_{r}$ is the relative temperature coefficient of the triplejunction CPV cells efficiency. Both $\eta_{r}$ and $\beta_{r}$ change with the concentration factor.

3.4. Heat Transfer Coefficients and Pressure Drop Correlations. Depending on the model mentioned above, the forced convection heat transfer coefficients (HTCs) between the turbulent immersion liquid and both the aluminium plate $\left(h_{p f}\right)$ and the triple-junction CPV module $\left(h_{c f 1}, h_{c f 2}\right)$ or the glass cover $\left(h_{g f}\right)$ are calculated by the following correlation [22]:

$$
\begin{aligned}
h= & \frac{\lambda_{f}}{D_{h}}\left\{\frac{\left(f_{p} / 8\right)(\operatorname{Re}-1000) \operatorname{Pr}}{1+12.7\left(f_{p} / 8\right)^{1 / 2}\left(\operatorname{Pr}^{2 / 3}-1\right)}[1\right. \\
& \left.\left.+\left(\frac{D_{h}}{L}\right)^{2 / 3}\right]\right\},
\end{aligned}
$$

where

$$
f_{p}=(1.82 \lg \operatorname{Re}-1.64)^{-2} ;
$$

$\lambda_{f}$ is the thermal conductivity of the immersion liquid, Re is Reynolds number, Pr is Prandtl number, $f_{p}$ is Moody (or Darcy) friction factor, $D_{h}$ is hydraulic diameter, and $L$ is the length of the channel. This correlation applies to Re in the range of $2300 \sim 10^{6}$ and $\mathrm{Pr}$ in the range of $0.6 \sim 10^{5}$.

The convection HTCs between the air and both the aluminium plate $\left(h_{p a}\right)$ and the glass cover $\left(h_{a g}\right)$ or the concentrator $\left(h_{d a}\right)$ are considered to be related to the wind speed $w$ using the correlation as follows [23]:

$$
h^{\prime}=5.7+3.8 w \text {. }
$$


The radiation HTCs between the sky and both the aluminium plate $\left(h_{r, p s}\right)$ and the concentrator $\left(h_{r, d s}\right)$ as well as the radiation HTC $\left(h_{r, d g}\right)$ between the concentrator and the glass cover are calculated by the formula of small subject 1 surrounded by big subject 2 :

$$
h_{r, 12}=\frac{\sigma \varepsilon_{1}\left(T_{1}^{4}-T_{2}^{4}\right)}{\left(T_{1}-T_{2}\right)},
$$

where $\sigma$ is Stefan-Boltzmann constant and $\varepsilon_{1}$ is the small subject 1 emissivity. The equivalent sky temperature $\left(T_{s}\right)$ is calculated by the following correlation [24]:

$$
T_{s}=0.0552 T_{a}^{1.5} .
$$

The radiation HTCs between the triple-junction CPV module and both the aluminium plate $\left(h_{r, p c}\right)$ and the glass cover $\left(h_{r, g c}\right)$ are evaluated by the relation of two infinite parallel plates $(3,4)$ :

$$
h_{r, 34}=\frac{\sigma\left(T_{3}+T_{4}\right)\left(T_{3}^{2}+T_{4}^{2}\right)}{\left(1 / \varepsilon_{3}+1 / \varepsilon_{4}-1\right)} .
$$

To determine the fluid pressure drop $\Delta P$, across the length of the receiver, the following equation is used [25]:

$$
\Delta P=f_{p} \frac{L}{D_{h}} \frac{\rho_{f} u^{2}}{2},
$$

where $\rho_{f}$ is density of immersion liquid and $u$ is the immersion liquid velocity in the receiver.

In (1)-(3) and (5)-(6), the unknowns are five: aluminium plate temperature $\left(T_{p}\right)$, triple-junction solar cells temperature $\left(T_{c}\right)$, outlet liquid temperature $\left(T_{f_{o}}\right)$, temperature of the glass cover $\left(T_{g}\right)$, and the concentrator temperature $\left(T_{d}\right)$. Since several equations presented above include radiation terms, we must use the numerical iterative techniques to solve the nonlinear equations.

The model mentioned above is based on steady-state assumption. But the assumption will be neglected when (1)-(3) and (5)-(6) consider the capacitive terms. Then, the differential equations will replace the algebraic equations, and they can be solved using Matlab.

The performance of the dense-array HCPV system can be evaluated by the electrical efficiency, which is given by

$$
\eta_{\mathrm{el}}=\frac{E_{\mathrm{PV}}}{I_{b} C_{\mathrm{PV}} A_{\mathrm{PV}}} .
$$

It should be mentioned that the inlet liquid temperature is set to $293 \mathrm{~K}$ when investigating the effects of concentration factor and mass flow rate on the electrical efficiency of the system.

\section{Model Validation}

Since the dense-array HCPV system has not been constructed, the experimental data is unavailable for the rigorous validation of the model discussed above. However, in order
TABLE 1: Model validation.

\begin{tabular}{lccc}
\hline$I_{b}\left(\mathrm{~W} / \mathrm{m}^{2}\right)$ & $T_{c}(\mathrm{~K})($ from $[15])$ & $T_{c}(\mathrm{~K})$ & Error $(\%)$ \\
\hline 801 & 314.8 & 305.0 & -3.1 \\
841 & 315.9 & 307.7 & -2.6 \\
904 & 318.6 & 329.4 & 3.4 \\
959 & 319.4 & 332.2 & 4.0 \\
985 & 320.0 & 334.7 & 4.6 \\
\hline
\end{tabular}

to demonstrate the model reliability, the results from the model were compared with the available experimental data in the literature which described a similar HCPV system [15]. The detailed procedures were performed as follows. First, the model discussed above was slightly changed to consider the use of back-contact CPV silicon solar cells. Second, the model was slightly changed by using the thermodynamic properties of deionized (DI) water, in order to consider DI water as the immersion liquid. Third, the design parameters and the operating parameters were input to the model according to the data from [15]. Then, the experimental data available in [15] were used to calibrate the model. Finally, the calibrated model was applied to calculate the average temperature of solar module in the HCPV system. The analysis proved that the model exhibits acceptable errors in calculating the average temperature of solar PV module in the HCPV system; see Table 1.

\section{Results and Discussion}

The model has been applied to investigate the components temperatures of the direct liquid immersion solar receiver and the electrical performance of the dense-array HCPV system under different operating condition. To do so, Table 2 lists the input parameters of the model. Some values presented in Table 2 are obtained from the literatures. Otherwise, the reasonable estimations are made.

Dimethyl silicon oil is specified as the dielectric liquid flowing inside the receiver. The dimethyl silicon oil is produced by Shin-Etsu Chemical Co., Ltd., Japan, with the name KF-96L-2cs. Its thermodynamic properties are obtained from the technical datasheet. The measured spectral transmittance curve of the dimethyl silicon oil is observed in Figure 3. Also included is the spectral irradiance (Direct Normal + circumsolar at AM1.5, ASTM G173-03). From Figure 3, it can be seen that the dimethyl silicon oil is quite transparent in the wavelength range between $300 \mathrm{~nm}$ and $1800 \mathrm{~nm}$, over which the triple-junction solar cells absorb strongly.

5.1. Effects of the Concentration Factor. As mentioned above, both $\eta_{r}$ and $\beta_{r}$ of the triple-junction CPV cells change with the increasing concentration factor. These values utilized for $\eta_{r}$ and $\beta_{r}$ are derived from [26]. Figure 4 shows the influence of concentration factor on the system electrical conversion efficiency. It can be observed that the system electrical conversion efficiency rises firstly and then drops with the concentration factor increases. This is because the operating temperature of the triple-junction CPV cells increases as the 
TABLE 2: Parameters used for the models.

\begin{tabular}{lccc}
\hline Symbol & Unit & Value & Explanation \\
\hline$\alpha_{p}$ & 1 & 0.32 & From [27] \\
$\varepsilon_{p}$ & 1 & 0.10 & From [27] \\
$\alpha_{c}$ & 1 & 0.95 & From [28] \\
$\varepsilon_{c}$ & 1 & 0.20 & From [29] \\
$\alpha_{g}$ & 1 & 0.015 & From [27] \\
$\varepsilon_{g}$ & 1 & 0.90 & From [30] \\
$\alpha_{d}$ & 1 & 0.03 & From [29] \\
$\varepsilon_{d}$ & 1 & 0.30 & From [29] \\
$\eta_{\text {opt }}$ & 1 & 0.85 & From [21] \\
$I_{\text {tot }}$ & $\mathrm{W} / \mathrm{m}^{2}$ & 1000 & From [29] \\
$I_{b}$ & $\mathrm{~W} / \mathrm{m}^{2}$ & 850 & From [26] \\
$\rho_{f}$ & $\mathrm{~kg} / \mathrm{m}^{3}$ & 873 & From datasheet \\
$c_{f}$ & $\mathrm{~J} / \mathrm{kg} / \mathrm{K}$ & 1800 & From datasheet \\
$\lambda_{f}$ & $\mathrm{~W} / \mathrm{m} / \mathrm{K}$ & 0.11 & From datasheet \\
$\mu_{f}$ & $\mathrm{~Pa} \cdot \mathrm{s}$ & 0.001746 & From datasheet \\
$A_{p}, A_{g}$ & $\mathrm{~m}{ }^{2}$ & 0.02 & Own estimation \\
\hline
\end{tabular}

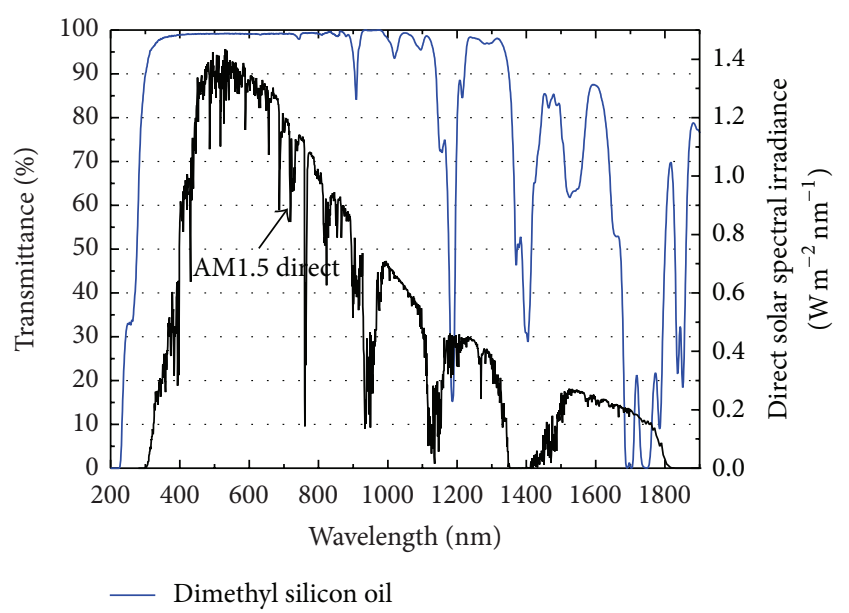

FIgURE 3: Spectral transmittance curve of dimethyl silicon oil, including spectral irradiance (AM1.5D, ASTM G173-03).

concentration factor increases, as shown in Figure 5. Furthermore, the system electrical conversion efficiency decreases with increasing operating temperature. Simultaneously, the system electrical conversion efficiency rises logarithmically with the increasing incident radiant. These two contrasting effects result in the electrical conversion efficiency of the designed system plot shown in Figure 4.

In addition, it can be seen from Figure 5 that the operating temperature of the CPV cells increases from $305 \mathrm{~K}$ to $368 \mathrm{~K}$ as the concentration factor increases from 100 suns to 600 suns. Therefore, in order to maintain the higher system efficiency at higher concentration factor, the other related parameters need to be changed to keep the concentrator solar cells operated in the optimized temperature range, especially the mass flow rate. This point is also verified by Figure 4 . Here, it is indicated that as the concentration factor rises, the increase in the mass flow rate accordingly is very significant to obtain

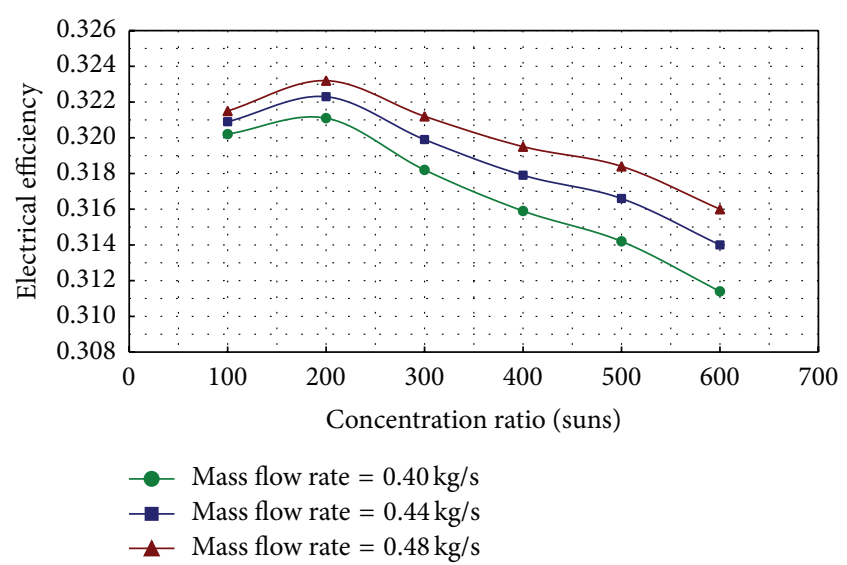

FIGURE 4: Dependence of the electrical efficiency of the system on the concentration factor $\left(T_{f_{i}}=293 \mathrm{~K}, T_{a}=298 \mathrm{~K}\right.$, and $\left.w=3 \mathrm{~m} / \mathrm{s}\right)$.

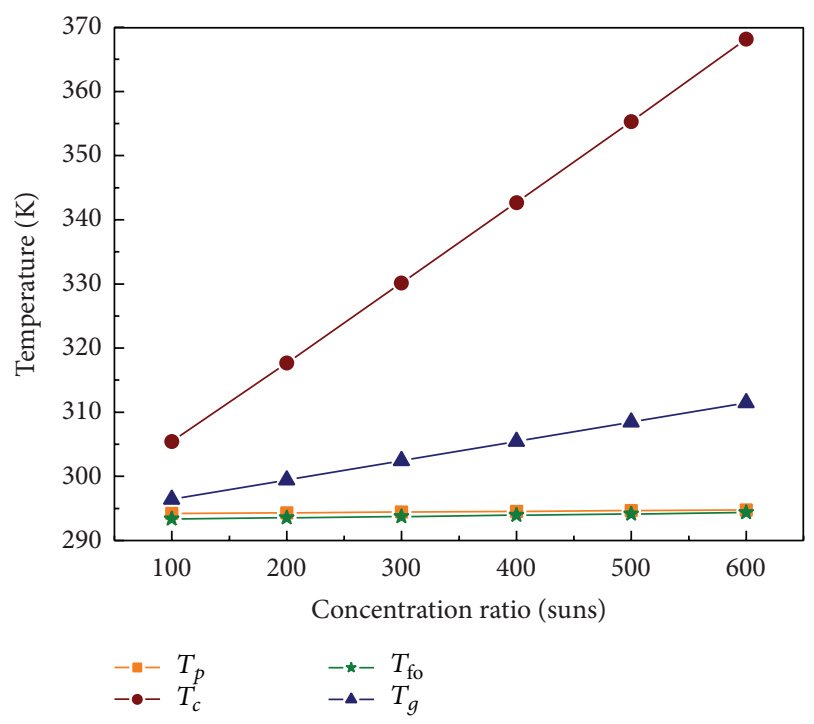

Figure 5: Dependence of the components temperatures of the receiver on the concentration factor $\left(m_{f}=0.40 \mathrm{~kg} / \mathrm{s}, T_{f_{i}}=293 \mathrm{~K}\right.$, $T_{a}=298 \mathrm{~K}$, and $w=3 \mathrm{~m} / \mathrm{s}$ ).

higher system electrical conversion efficiency. The electrical conversion efficiency of the HCPV system remains higher than $31 \%$ when the concentration factor reaches 600 suns.

5.2. Effects of Mass Flow Rate. The mass flow rate is changed from 0.38 to $0.58 \mathrm{~kg} / \mathrm{s}$ in 0.02 increments for dimethyl silicon oil to investigate its influence on the system electrical conversion efficiency and the components temperatures of the receiver. These mass flow rates represent the turbulent convection heat transfer region. In Figures 6 and 7, the concentration factor is held constant at 400 suns and the inlet liquid temperature is chosen to be $293 \mathrm{~K}$. As shown in Figure 6, the system electrical conversion efficiency increases with mass flow rate increases, and the operating temperature of the triple-junction CPV cells decreases as observed in Figure 7. This is mainly because the convection HTC increases 


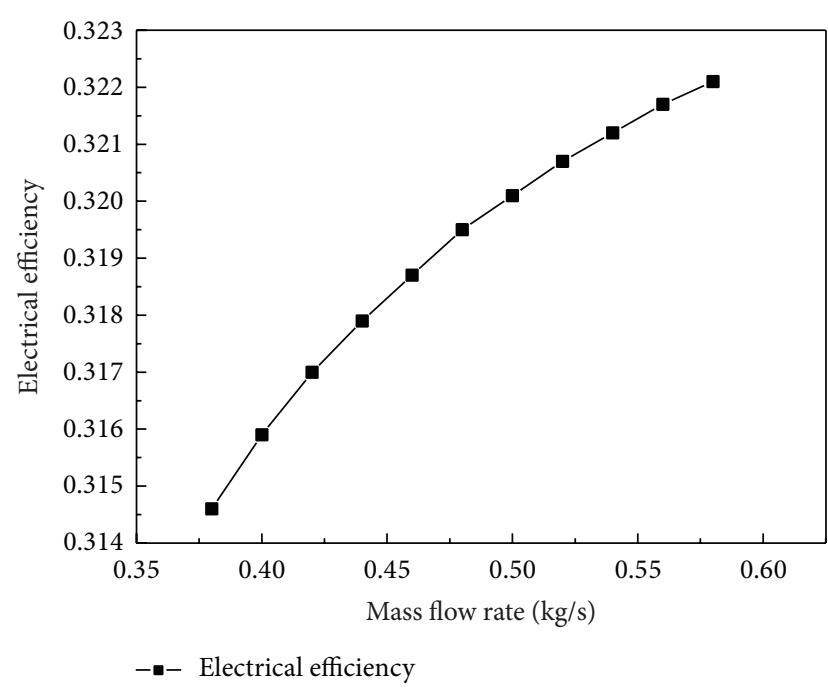

Figure 6: Dependence of the electrical efficiency of the system on the mass flow rate $\left(C_{\mathrm{PV}}=400 X, T_{f_{i}}=293 \mathrm{~K}, T_{a}=298 \mathrm{~K}\right.$, and $w=3 \mathrm{~m} / \mathrm{s}$ ).

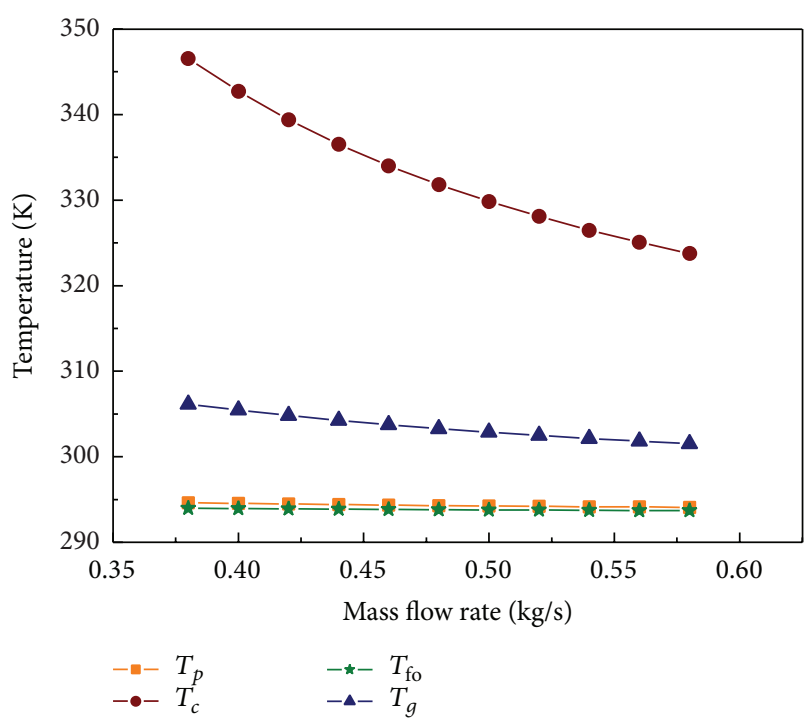

FIGURE 7: Dependence of the components temperatures of the receiver on the mass flow rate $\left(C_{\mathrm{PV}}=400 X, T_{f_{i}}=293 \mathrm{~K}, T_{a}=\right.$ $298 \mathrm{~K}$, and $w=3 \mathrm{~m} / \mathrm{s}$ ).

with the increase in mass flow rate. The more cooling mass brings the operating temperature of the triple-junction CPV cells down for the constant heat flux condition. Therefore, the higher mass flow rates resulted in the higher system electrical conversion efficiency.

The required pumping power to circulate the immersion cooling liquid is determined from the fluid pressure drop, with higher fluid pressure drop reducing the net amount of energy actually gained from the dense-array HCPV system. Figure 8 presents the pressure drop of dimethyl silicon oil when the receiver has a channel height of $0.01 \mathrm{~m}$ and the inlet liquid temperature of $293 \mathrm{~K}$. As expected, the results show that the fluid pressure drop increases with the mass flow rate, but the absolute value of the frictional pressure drop is much

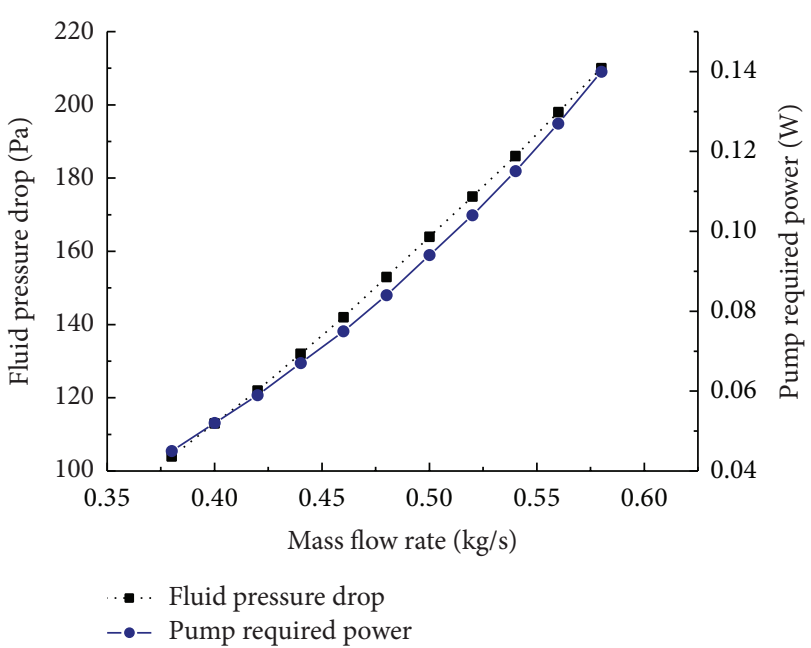

FIGURE 8: Fluid pressure drop and the required power by an ideal pump to circulate the immersion liquid across the receiver as functions of the mass flow rate.

smaller for the current receiver. The required pumping power input of an ideal, isentropic pump can then be calculated using the following formula [25]:

$$
W=V_{f} \Delta P,
$$

where $V_{f}$ is the volumetric flow rate of the immersion liquid.

The estimated pumping power required for the corresponding fluid pressure drop from Figure 8 is also presented in Figure 8. It can be seen clearly that the required pumping power increases for larger mass flow rates. In fact, at higher mass flow rates, the effect of the mass flow rate on the operating temperature of the triple-junction CPV cells and thus on the system efficiency is reduced. Therefore, finding the optimum mass flow rate that resulted in higher system electrical conversion efficiency and lower cost will introduce further work.

5.3. Effects of Inlet Liquid Temperature. Inlet liquid temperature is another parameter which can affect the components temperatures of the solar receiver and thus the system output power. The components temperatures of the receiver for different inlet dimethyl silicon oil temperatures are shown in Figure 9 with the concentration factor of 400 suns and a mass flow rate of $0.40 \mathrm{~kg} / \mathrm{s}$. It can be observed that the increase in the inlet liquid temperature results in the triple-junction $\mathrm{CPV}$ cells temperature increase. This phenomenon makes a decrease in the system electrical conversion efficiency. Therefore, the lower inlet liquid temperatures correlated with the higher system electrical conversion efficiency when holding all other parameters constant. It can be also observed from Figure 9 that the increase in the inlet liquid temperature results in the increase of the glass cover temperature and the aluminium plate temperature, causing also the outlet liquid temperature rise. Therefore, the conclusion can be made that the inlet liquid temperature plays an important role in the system output power. In order to maximise the system 


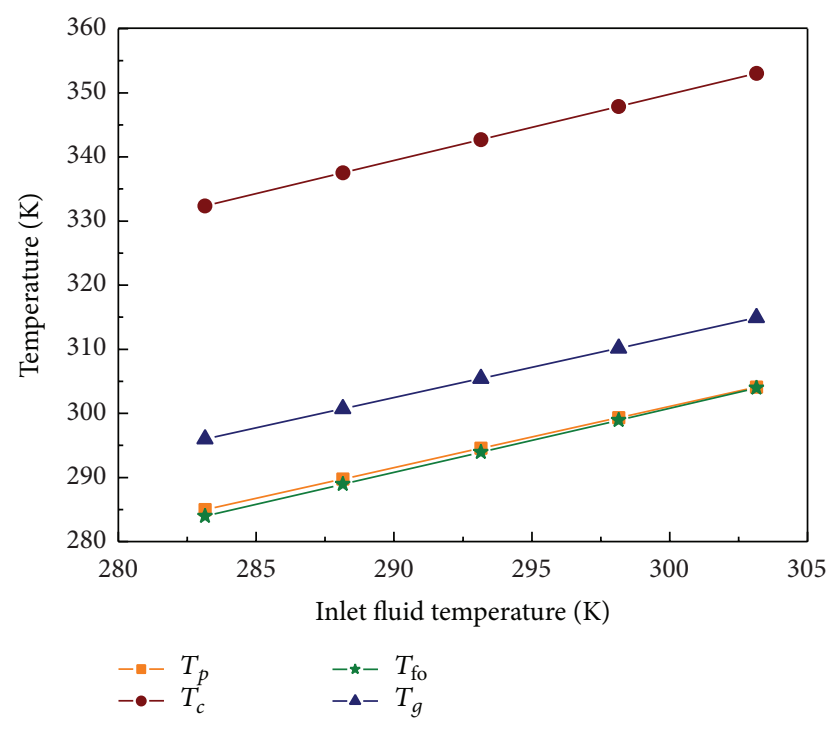

FIGURE 9: Dependence of the components temperatures of the receiver on inlet liquid temperature $\left(C_{\mathrm{PV}}=400 X, m_{f}=0.40 \mathrm{~kg} / \mathrm{s}\right.$, $T_{a}=298 \mathrm{~K}$, and $w=3 \mathrm{~m} / \mathrm{s}$ ).

electrical conversion efficiency, the inlet liquid temperature should be kept as low as possible.

\section{Conclusions}

The main novelty of the dense-array HCPV system with triple-junction CPV cells is the combination of a dish concentrator with a direct liquid-immersed solar receiver. A theoretical model of the direct liquid-immersed solar receiver with triple-junction CPV cells has been described. The results prove the technical feasibility of direct liquid immersion cooling for a dense-array HCPV system based on triplejunction CPV cells. In addition, the simulation results show that the electrical conversion efficiency of the dense-array HCPV system is very high for a series of operating conditions. The concentration factor, the mass flow rate, and the inlet liquid temperature have a major effect on the temperature of the triple-junction CPV cells and, by extension, system output power. The flow rate selection should match the concentration factor to keep the triple-junction CPV cells temperature lower and increase the electrical conversion efficiency of the dense-array HCPV system.

The presented model allows the optimization of the direct liquid-immersed solar receiver and the dense-array HCPV system. The effect of any design parameter changes on the electrical conversion efficiency of the dense-array HCPV system can be obtained. Moreover, for a given design and set of operating parameters, the model can be used to compute the annual electrical output of the dense-array HCPV system.

\section{Nomenclature}
A : Area, $\mathrm{m}^{2}$
C: Concentration ratio
c: $\quad$ Specific heat, $\mathrm{J} /(\mathrm{kg} \cdot \mathrm{K})$

$D_{h}:$ Hydraulic diameter, $\mathrm{m}$

$E$ : Electrical power output, W

$f_{p}$ : Friction factor

$G$ : Radiation focused on the solar cells, W

$h$ : Heat transfer coefficient, $\mathrm{W} /\left(\mathrm{m}^{2} \cdot \mathrm{K}\right)$

$I_{\text {tot }}$ : Total radiation, $\mathrm{W} / \mathrm{m}^{2}$

$I_{b}$ : Beam radiation, $\mathrm{W} / \mathrm{m}^{2}$

$L: \quad$ Length, $\mathrm{m}$

$m$ : Mass flow rate, $\mathrm{kg} / \mathrm{s}$

$\mathrm{Nu}$ : Nusselt number

Re: Reynolds number

Pr: Prandtl number

$P$ : Pressure, $\mathrm{Pa}$

Q: Power, W

R: Reflectivity

T: Temperature, $\mathrm{K}$

u: Velocity, $\mathrm{m} / \mathrm{s}$

$V:$ Volumetric flow rate, $\mathrm{m}^{3} / \mathrm{s}$

$w$ : Wind speed, $\mathrm{m} / \mathrm{s}$

$W$ : Required pumping power, $\mathrm{W}$.

\section{Greek Symbols}

$\alpha$ : Absorptance

$\beta$ : Relative temperature coefficient of the solar cell efficiency, $\%_{\text {rel }} / \mathrm{K}$

$\varepsilon$ : Emissivity

$\lambda$ : Thermal conductivity, $\mathrm{W} /(\mathrm{m} \cdot \mathrm{K})$

$\mu$ : Dynamic viscosity, Pa.s

$\rho:$ Density, $\mathrm{Kg} / \mathrm{m}^{3}$

$\sigma$ : Stefan-Boltzmann constant, $\mathrm{W} /\left(\mathrm{m}^{2} \cdot \mathrm{K}^{4}\right)$

$\eta$ : Efficiency.

$\begin{array}{ll}\text { Subscripts } \\ a: & \text { Ambient efficiency } \\ c: & \text { Triple-junction solar cells } \\ d: & \text { Dish concentrator } \\ f: & \text { Fluid } \\ f_{i}: & \text { Inlet fluid } \\ f_{o}: & \text { Outlet fluid } \\ g: & \text { Glass } \\ m: & \text { Mean } \\ \text { modu: } & \text { Solar module } \\ \text { opt: } & \text { Optical } \\ p: & \text { Aluminium plate } \\ \text { pv: } & \text { Photovoltaic } \\ s: & \text { Sky } \\ r: & \text { Reference or radiative } \\ \text { el: } & \text { Electrical. }\end{array}$

\section{Conflict of Interests}

The authors declare that there is no conflict of interests regarding the publication of this paper.

\section{Acknowledgments}

This work was financially supported by National Natural Science Foundation of China (51306077), Natural 
Science Foundation of Jiangsu Province (BK20130518), Natural Science Foundation of Jiangsu Colleges and Universities (13KJB480002), China Postdoctoral Science Foundation (2014M551513), Postdoctoral Science Foundation of Jiangsu Province (1401141C), and Training Project for Young Teachers of Jiangsu University.

\section{References}

[1] M. A. Green, K. Emery, Y. Hishikawa, W. Warta, and E. D. Dunlop, "Solar cell efficiency tables (version 46)," Progress in Photovoltaics: Research and Applications, vol. 23, no. 7, pp. 805812, 2015.

[2] M. Wiesenfarth, H. Helmers, S. P. Philipps, M. Steiner, and A. W. Bett, "Advanced concepts in concentrating photovoltaics (CPV)," in Proceedings of the 27th European Photovoltaic Solar Energy Conference and Exhibition (PVSEC '12), pp. 11-15, 2012.

[3] A. Royne, C. J. Dey, and D. R. Mills, "Cooling of photovoltaic cells under concentrated illumination: a critical review," Solar Energy Materials and Solar Cells, vol. 86, no. 4, pp. 451-483, 2005.

[4] K. Araki, H. Uozumi, and M. Yamaguchi, "A simple passive cooling structure and its heat analysis for $500 \times$ concentrator PV module," in Proceedings of the 29th IEEE Photovoltaic Specialist Conference (PVSC '02), pp. 1568-1571, May 2002.

[5] J. Sun, T. Israeli, T. A. Reddy, K. Scoles, J. M. Gordon, and D. Feuermann, "Modeling and experimental evaluation of passive heat sinks for miniature high-flux photovoltaic concentrators," Journal of Solar Energy Engineering, vol. 127, no. 1, pp. 138-145, 2005.

[6] Y. N. Wang, T. T. Lin, J. C. Leong et al., "Numerical investigation of high-concentration photovoltaic module heat dissipation," Renewable Energy, vol. 50, pp. 20-26, 2013.

[7] J. B. Lasich, "Cooling circuit for receiver of solar radiation," US Patent 7,076,965, 2006.

[8] K.-K. Chong and W.-C. Tan, "Study of automotive radiator cooling system for dense-array concentration photovoltaic system," Solar Energy, vol. 86, no. 9, pp. 2632-2643, 2012.

[9] T. Ho, S. S. Mao, and R. Greif, "Improving efficiency of highconcentrator photovoltaics by cooling with two-phase forced convection," International Journal of Energy Research, vol. 34, no. 14, pp. 1257-1271, 2010.

[10] T. Ugumori and M. Ikeya, "Efficiency increase of solar cells operated in dielectric liquid," Japanese Journal of Applied Physics, vol. 20, pp. 77-80, 1981.

[11] Y. A. Abrahamyan, V. I. Serago, V. M. Aroutiounian et al., "The efficiency of solar cells immersed in liquid dielectrics," Solar Energy Materials and Solar Cells, vol. 73, no. 4, pp. 367-375, 2002.

[12] Y. P. Wang, Z. L. Fang, L. Zhu, Q. W. Huang, Y. Zhang, and Z. Y. Zhang, "The performance of silicon solar cells operated in liquids," Applied Energy, vol. 86, no. 7-8, pp. 1037-1042, 2009.

[13] X. Y. Han, Y. P. Wang, and L. Zhu, "Electrical and thermal performance of silicon concentrator solar cells immersed in dielectric liquids," Applied Energy, vol. 88, no. 12, pp. 4481-4489, 2011.

[14] Y. Sun, Y. P. Wang, L. Zhu, B. Q. Yin, H. J. Xiang, and Q. W. Huang, "Direct liquid-immersion cooling of concentrator silicon solar cells in a linear concentrating photovoltaic receiver," Energy, vol. 65, pp. 264-271, 2014.
[15] L. Zhu, R. F. Boehm, Y. Wang, C. Halford, and Y. Sun, "Water immersion cooling of PV cells in a high concentration system," Solar Energy Materials and Solar Cells, vol. 95, no. 2, pp. 538$545,2011$.

[16] M. Blanco-Muriel, D. C. Alarcón-Padilla, T. López-Moratalla, and M. Lara-Coira, "Computing the solar vector," Solar Energy, vol. 70, no. 5, pp. 431-441, 2001.

[17] I. Mahderekal, C. K. Haiford, and R. F. Boehm, "Simulation and optimization of a concentrated photovoltaic system," Journal of Solar Energy Engineering, vol. 128, no. 2, pp. 139-145, 2006.

[18] S. S. Lee, S. O. Lai, and K. K. Chong, "A study on cooling of concentrator photovoltaic cells using CFD," in Proceedings of the International Conference on Innovation, Management and Technology Research (ICIMTR '12), pp. 403-406, May 2012.

[19] A. Buonomano, G. Mittelman, D. Faiman et al., "Modelling an actively-cooled CPV system," in Proceedings of the 8th International Conference on Concentrating Photovoltaic Systems (CPV '12), pp. 235-238, Toledo, Spain, April 2012.

[20] F. Al-Amri and T. K. Mallick, "Alleviating operating temperature of concentration solar cell by air active cooling and surface radiation," Applied Thermal Engineering, vol. 59, no. 1-2, pp. 348-354, 2013.

[21] G. Mittelman, A. Kribus, and A. Dayan, "Solar cooling with concentrating photovoltaic/thermal (CPVT) systems," Energy Conversion and Management, vol. 48, no. 9, pp. 2481-2490, 2007.

[22] F. P. Incropera and D. P. Dewitt, Fundamentals of Heat and Mass Transfer, John Wiley \& Sons, New York, NY, USA, 4th edition, 1996.

[23] S. Kumar and S. C. Mullick, "Wind heat transfer coefficient in solar collectors in outdoor conditions," Solar Energy, vol. 84, no. 6, pp. 956-963, 2010.

[24] A. A. Hegazy, "Comparative study of the performances of four photovoltaic/thermal solar air collectors," Energy Conversion and Management, vol. 41, no. 8, pp. 861-881, 2000.

[25] Y. A. Cengel, Heat Transfer-A Practical Approach, McGraw-Hill, New York, NY, USA, 2nd edition, 2003.

[26] H. Helmers, A. W. Bett, J. Parisi, and C. Agert, "Modeling of concentrating photovoltaic and thermal systems," Progress in Photovoltaics: Research and Applications, vol. 22, no. 4, pp. 427439, 2014.

[27] J. S. Coventry, A solar concentrating photovoltaic/thermal collector [Ph.D. thesis], Australian National University, Canberra, Australia, 2004.

[28] H. Chen, J. Ji, Y. Wang, W. Sun, G. Pei, and Z. Yu, “Thermal analysis of a high concentration photovoltaic/thermal system," Solar Energy, vol. 107, pp. 372-379, 2014.

[29] F. Calise and L. Vanoli, "Parabolic trough photovoltaic/thermal collectors: design and simulation model," Energies, vol. 5, no. 10, pp. 4186-4208, 2012.

[30] J. I. Rosell, X. Vallverdú, M. A. Lechón, and M. Ibáñez, “Design and simulation of a low concentrating photovoltaic/thermal system," Energy Conversion and Management, vol. 46, no. 18-19, pp. 3034-3046, 2005. 

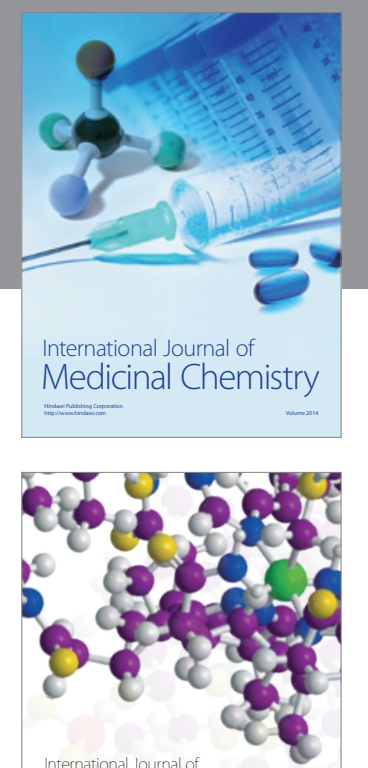

\section{Carbohydrate} Chemistry

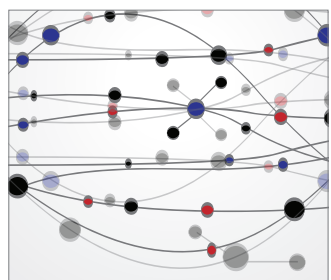

The Scientific World Journal
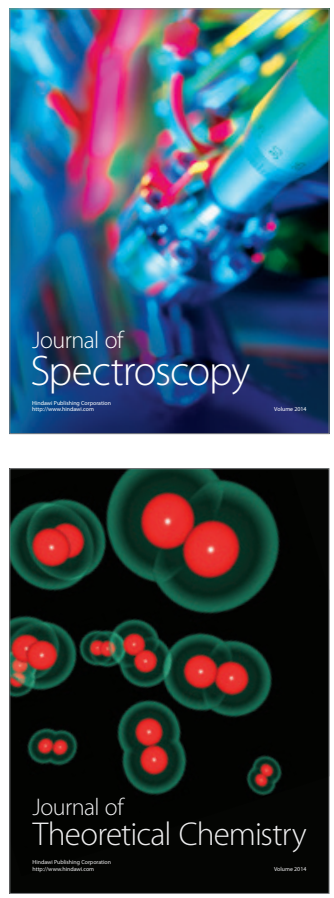
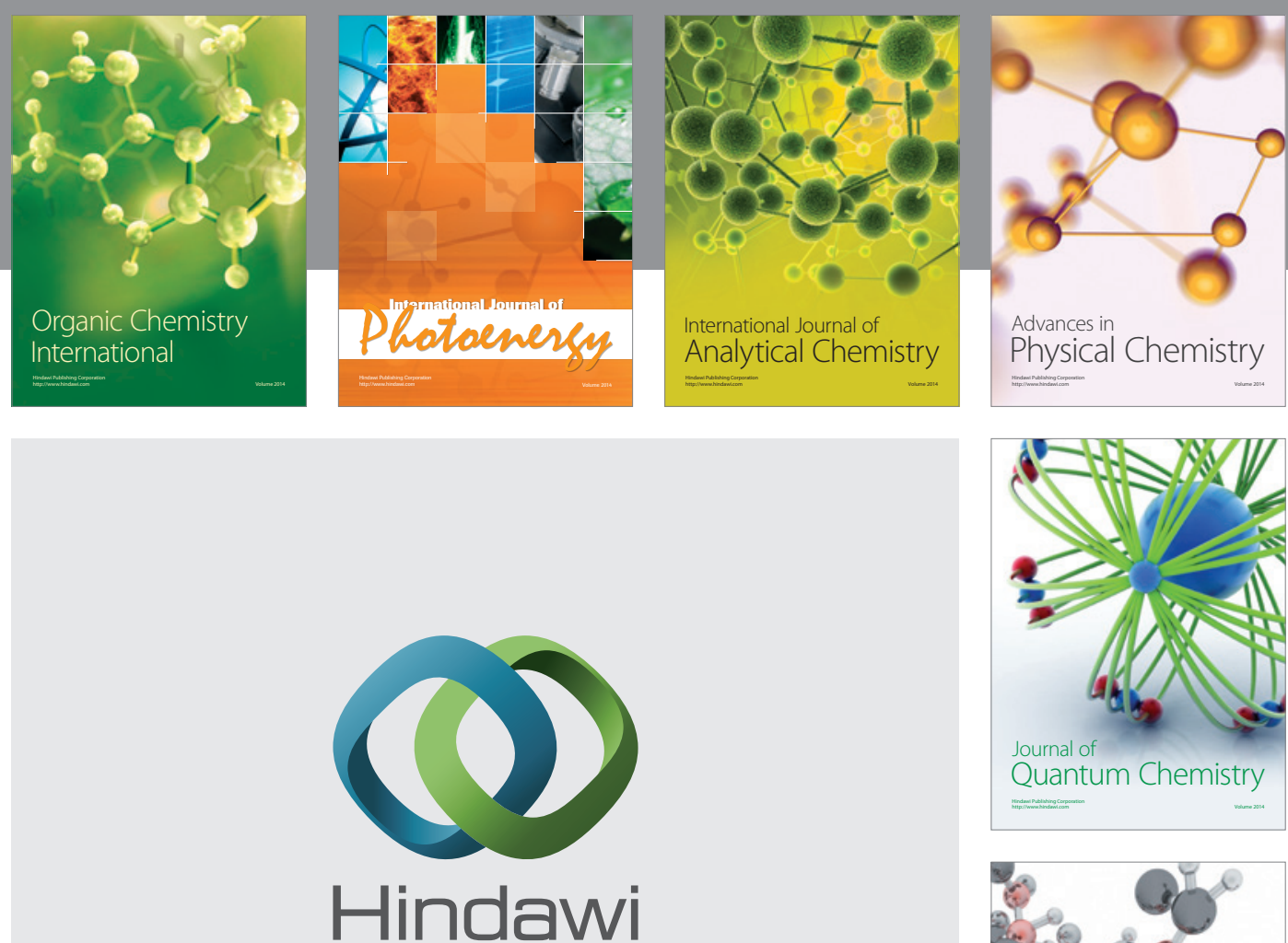

Submit your manuscripts at

http://www.hindawi.com

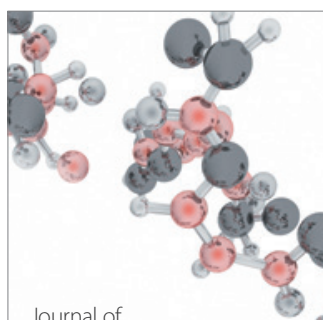

Analytical Methods

in Chemistry

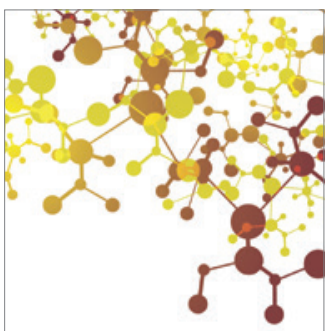

Journal of

Applied Chemistry

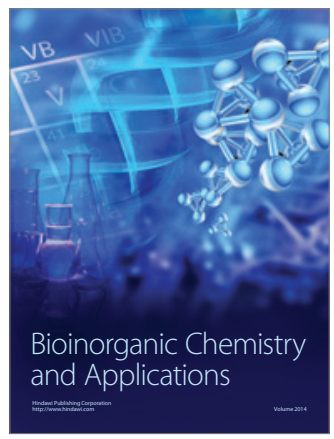

Inorganic Chemistry
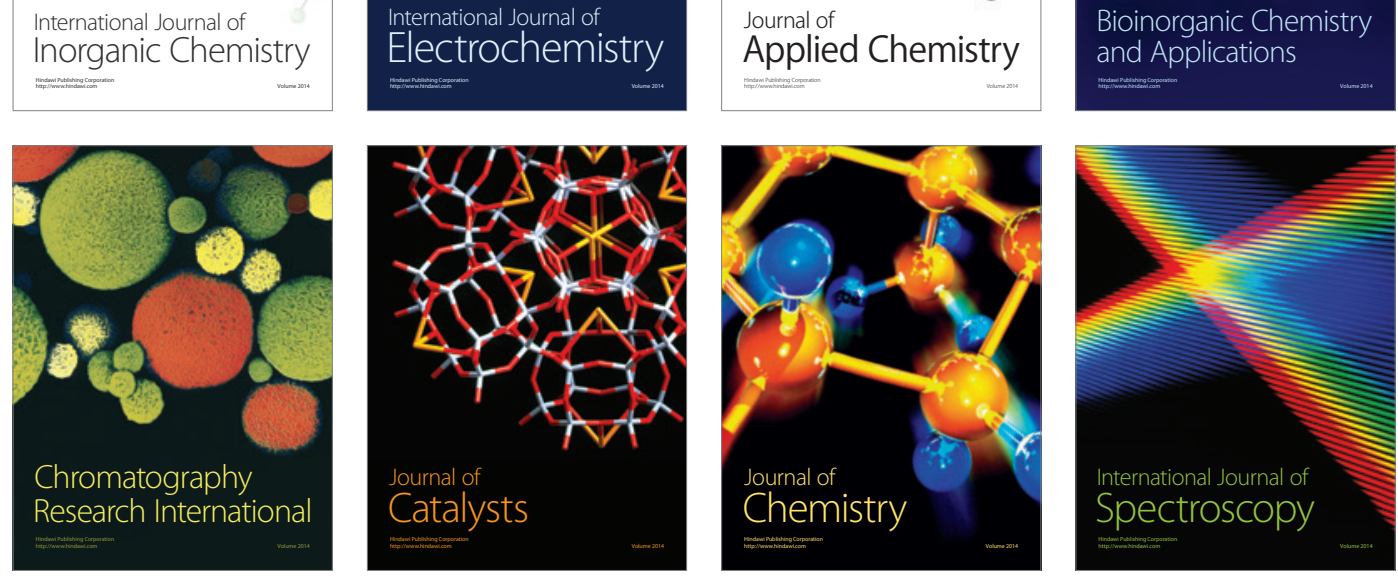